\title{
A Review on Revolution of Pharmaceutical Sector in Bangladesh after Liberation War and Future Prospects and Challenges
}

\author{
Sakib Mosharraf, Mohammad Salim Hossain, Md. Abdul Barek*, Hrishov Das, Md. Abdur Rahman Ripon \\ Department of Pharmacy, Noakhali Science and Technology University, Sonapur, Noakhali, BANGLADESH.
}

\begin{abstract}
Pharmaceutical is the core of Bangladesh's Healthcare sector with an annual average growth rate consistently in the double digits. The real growth of local pharmaceutical industries started after the "Drug Control Ordinance-1982". Objective of the review is to identify the historical background, explore the overall situation and future opportunities of Pharmaceutical industry of Bangladesh. In Bangladesh overall growth of industries virtually polarized in three big metropolitan areas of Dhaka, Chittagong and Khulna, mainly in Dhaka. Presently, the industry meets $97 \%$ of local demand and exports to more than 80 countries. As a Least Developed Country (LDC), the country is exempted from obligations to implement patents and data protection for pharmaceutical products until 2033. Generic drugs in Bangladesh estimates to reach BDT 30,300 core by 2024. A number of companies have achieved accreditation from different world-famous regulatory bodies like US-FDA, UK-MHRA, Australia-TGA, EU for quality management and quality products manufacturing. A local industry supporting drug policy and effective regulatory framework, along with trade related
\end{abstract}

aspects of intellectual property rights relaxations are the key reasons for success of the industry. Prime Minister Sheikh Hasina has named pharmaceuticals the Product of the Year for 2018. Prospect of the sector depends largely on the interactions among the proprietors, regulatory bodies and the government, whether they can meet up the requisites to continue growth of the sector while facing the challenge.

Key words: Pharmaceutical, Generic, Trade, Drug policy, Prospect.

\section{Correspondence}

Md. Abdul Barek,

Department of Pharmacy, Faculty of Science, Noakhali Science and Technology University, Sonapur, Noakhali-3814, BANGLADESH.

Phone no: +8801930684828

Email: barekpharma@gmail.com

DOI: 10.5330/ijpi.2019.3.18

\section{INTRODUCTION}

The pharmaceutical industries are one of the most promising sector and second-largest contributor to the government exchequer with an annual turnover of about $\$ 715$ million. ${ }^{1}$ Bangladesh's pharmaceutical industry contributes almost $1.85 \%$ of GDP. ${ }^{2}$ Skillful attitudes, knowledge and innovative ideas from the professionals are the key reasons why this industry grew in the way it did. The country's pharmaceutical sector has been one of the success stories of Bangladesh in the last three decades. ${ }^{3}$ This sector started to improve from 1980s. ${ }^{4}$ The Drug (Control) Ordinance in 1982 was the key factor of success of pharmaceutical industries in Bangladesh. ${ }^{5}$ In 1981, there were 166 licensed pharmaceutical manufacturers in the country, but local production was dominated by eight Multinational Companies (MNCs) which manufactured about $75 \%$ of the products. ${ }^{6,7}$ There were 25 medium sized local companies which manufactured $15 \%$ of the products and the remaining $10 \%$ were produced by other 133 small local companies. ${ }^{8}$ The value of locally produced medicines rose from Tk 1.1 million in 1981 to Tk 187,566 million 2017. ${ }^{9}$ Government has set target to earn $\$ 5$ billion from the pharmaceuticals by $202 .{ }^{9}$ Two decades ago, most of the drugs needed to be imported. In the current scenario, as the national companies are taking over, about $97 \%$ need is fulfilled domestically while $3 \%$ are covered by imports. ${ }^{10,11}$ According to the information of the Director General of Drug Administration of Bangladesh (DGDA) now there are 271 Allopathic, 268 Unani, 205 Ayurvedic, 79 Homeopathic, Herbal 32 drug manufacturing companies in Bangladesh. ${ }^{12}$ Bangladeshi pharmaceutical firms focus primarily on branded generic final formulations using imported APIs (Active Pharmaceutical Ingredients). According to Director General of Drug Administration (DGDA), the industry has 3,575 generics of Allopathic medicine, 2313 registered Homeopathic drugs, 6046 registered
Unani Drugs and 3,966 registered Ayurvedic drugs and 506 registered Herbal drug. ${ }^{13}$ Annual growth rate of Bangladesh pharmaceutical market about $11.37 \% .{ }^{14}$ Sales of generic drugs in Bangladesh will treble to BDT 30,300 core per year by $2024 .{ }^{15}$ However, the trend now seems to be favorable to the country as the domestic pharmaceutical industry as well as the companies from neighboring countries like India, China and even MNCs have queued up to put in investments on this front as every stakeholder will benefit of vast potential that Bangladesh can offer. With the development of healthcare infrastructure and increase of health awareness and the purchasing capacity of people, this industry is expected to grow at a higher rate in future. Healthy growth is likely to encourage the pharmaceutical companies to introduce newer drugs and newer research products, while at the same time maintaining a healthy competitiveness in respect of the most essential drugs. In this review, the past and current scenario of pharmaceutical industries of Bangladesh has been presented along with an analysis of its prospects and challenges. We investigate the historical background of pharmaceutical industry of Bangladesh, education system, overall situation of Pharmaceutical industry of Bangladesh, growth projection of this industry and future prospects and challenges.

\section{METHODS}

This research is based on Primary and secondary data which together provided more comprehensive information. Collected data has been analyzed on the basis of the objective of the study. Primary data is open discussion method was followed to gather primary information by informally interviewing the various Departmental Head, executives of the company. Secondary data were collected from the existing writing in the field of both local and international pharmaceutical part. It has been 
used combined information collected from several recognized journals, magazines, newspapers and websites of both local and international pharmaceutical companies and various published materials on the topic.

\section{RESULTS}

\section{Historical Background of Bangladesh Pharmaceutical Industry}

The National Drug Policy (NDP) in 1982 and 2005 has major impact in the development and growth of the Bangladesh pharmaceutical industry. ${ }^{16,17}$ The Census Manufacturing Industries 1983-84 has shown that over 88 percent of the total industrial assets have found accommodation in Dhaka and Chittagong divisions, while only 5.82 percent and 5.15 percent of the capital formation- took place in Khulna and Rajshahi divisions respectively. ${ }^{18}$ The land price of Dhaka was very high among other districts. Mainly land prices in the areas of Dhaka Metropolitan city were too high. To reduce land cost Drug industries are gradually moving towards fringe areas. Labor cost of different pharmaceutical industries varies from company to company. For skilled labor the monthly wages varies between Tk.700 to Tk. 5000 and for unskilled labor the monthly wages varies between Tk. 400 to Tk. $2990 .{ }^{18}$ Drug Industries depend on Imported Raw Materials. About 68 to over 77 percent raw materials of different drug industries of are imported from foreign countries. ${ }^{18}$ Table 1 shows Bangladesh Pharmaceutical Market Prior to 1982.

\section{Pharmaceutical Regulations: Relevant Laws and the Regulatory Body}

In Bangladesh, key legislation relating to pharmaceuticals includes the Drugs Act, 1940 and its amendments (the Drug Rules, 1945 and the Drug Rules, 1946); and the Drugs (Control) Ordinance, 1982 (DCO 1982) and its amendments [Drug (Control) (Amendment) Ordinance, 1984 and Drugs (Control) (Amendment) Act, 2006. The Drugs Act, 1940 regulates the import, export, manufacture, distribution and sale of pharmaceuticals in Bangladesh ${ }^{19,20}$ (Table 2). The Act was originally enacted by the Government of India in 1940, was adopted by the Government of Pakistan in 1957 and then subsequently adopted in Bangladesh in 1974 (20).

\section{Pharmaceutical Education}

Professor Dr. Abdul Jabbar was the initiator of Pharmacy education in Dhaka University (21). Pharmacy Department was started by starting B. Pharm degree in 1964 this is converted to B. Pharm (Hons) in 1965. First M. Pharm course started in $1969 .{ }^{21}$ Currently, there are 12 public universities and 31 private universities in Bangladesh offering Bachelor of Pharmacy and Masters of Pharmacy Programs. ${ }^{22}$ In addition, there are 50 colleges/institutes in Bangladesh offering Diploma in Pharmacy program. Most of the universities are offering 4 years Bachelor degree and 1 year master degree.22 Pharmacists having 'A' grade registration are eligible to Practice Pharmacy in Bangladesh but now registration examination is off. ${ }^{23}$ The $\mathrm{PCB}$ provides ' $\mathrm{B}$ ' grade registration to the students who have passed the 3-year diploma in Pharmacy course. ${ }^{24}$ Those who can pass 3-month special courses designed and jointly conducted by Bangladesh Pharmaceutical Society (BPS) and Bangladesh Chemists and Druggists Society (BCDS) are categorized as ' $C$ ' grade pharmacists by $\mathrm{PCB}$ and they usually work in community pharmacy or run their own pharmacies. ${ }^{24}$

\section{Present perspective Pharmaceutical Industries}

Domestic market of Pharmaceutical products in Bangladesh has shown an increasing trend over the past few years and the market size is BDT 187,556 million as on 2017 (Figure 1). ${ }^{25,26}$ According to industry experts,

market size of pharmaceuticals may reach about BDT 330,000 million by $2020 .^{27}$

The Executive Committee of the National Economic Council (ECNEC), gave green signal to the Active Pharmaceutical Ingredient (API) Park in Munshiganj recently at an overall project cost of Tk 2.13 billion. ${ }^{28} \mathrm{~A}$ total of 30 drug companies have already applied for plots at the API park. ${ }^{28}$ They have the money ready to establish plants. According to Bangladesh Association of Pharmaceutical Industries (BAPI), approximately 1,200 pharmaceutical products received registration for export over the last

Table 1: Bangladesh Pharmaceutical Market Prior to 1982.

\begin{tabular}{cc}
\hline Government Spending & BDT 1500 million per year \\
\hline Number of brands in market & 3500 \\
Number of manufactures & 177 \\
Multinationals & 8 \\
Retail Pharmacists & 16000 \\
Number of Wholesalers & 1300 \\
Private Sector & $90 \%$ available drugs \\
Government Utilize & $10 \%$ available drugs \\
\hline
\end{tabular}

Table 2: Milestones in the gradual development of pharmaceutical regulation in Bangladesh.

1940

1945

1946

1966

1970

1976

1982

1984

1992

2001

2002

2003

2005

2006

2009

$+2$

2010

2012

2016
Drugs Act (XXIII of 1940)

Drug Rules, 1945 (under the Drugs Act, 1940) Bengal Drugs Rules, 1946

Gazette of Pakistan: Office of the Chief Controller of Imports and Exports. Public Notice, 1966

Dacca Gazette, Part I: Government of East Pakistan, Health Department Notification, 1970

Directorate of Drug Administration (DDA), the national regulatory authority for drugs, is created

Drugs (Control) Ordinance, 1982, Drugs (Control) (Amendment) Ordinance, 1982 and National Drug Policy, 1982

Drugs (Control) (Amendment) Ordinance, 1984

Institute of Public Health produces tetanus vaccines First edition of the National Formulary published

WHO approves oral cholera vaccine tested at the International Centre for Diarrheal Disease Research, Bangladesh (ICDDR-B)

ICDDR-B studies establish that zinc treatment of diarrhea reduces under- 5 mortality by $50 \%$

Second edition of the National Formulary published National Drug Policy, 2005

Drug (Control) Ordinance Amendment Act, 2006 Third edition of the National Formulary published

South-East Asia Regional Office/Department of Family and Community Health/Immunization and Vaccine Development mission to discuss institutional development plan to build DDA capacity

DDA upgraded to the Directorate General of Drug Administration (DGDA) WHO mission to assess pharmaceuticals in healthcare delivery in Bangladesh

Revised New Drug Policy, 2012 drafted and submitted for approval DGDA has sent their recommendations for the proposed Drug Act 2016 and Drug Policy, 2016 to the Ministry of Health and Family Welfare. 


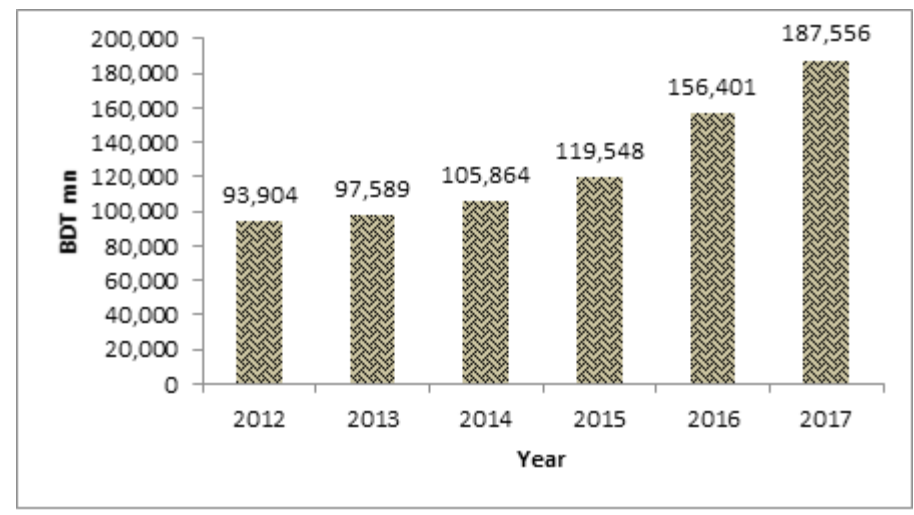

Figure 1: Pharmaceutical products of Bangladesh and growth (2012-2017).

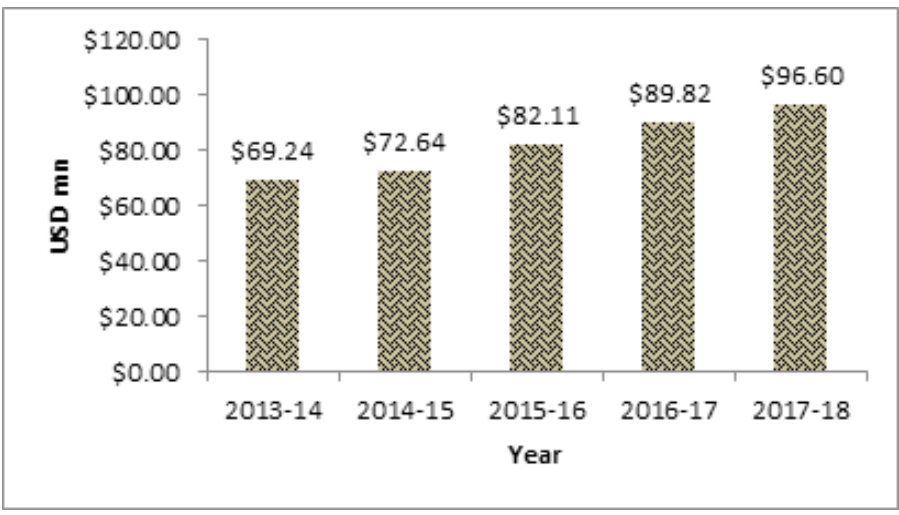

Figure 2: Export of Pharmaceutical Product of Bangladesh and Growth (USD $\mathrm{mn})$.

two years. ${ }^{29}$ According to Bangladesh Export Promotion Bureau, Bangladesh exported pharmaceuticals product to 107 countries in the fiscal year 2016-17. ${ }^{2,25}$ During this period, Bangladesh has exported pharmaceutical products worth USD 89.17 million as against USD 82.11 million in 2015-16 (Figure 2). 2,25

\section{DISCUSSION}

The pharmaceutical sector is one of the thrust sectors in Bangladesh. After several years of liberation, the government could not increase budgetary allocations for the improvement of health sector. This benevolent policy could not immediately win the approval of the people of Bangladesh, even though they had suffered from the high prices of important life-saving drugs. Instead the major newspapers regarded the policy as a hare-brained populist policy improvised by the military government and as doomed to be crushed by pressure from abroad. Indeed, the US ambassador came to Ershad immediately and began bringing relentless pressure on the Bangladesh government to reverse the decision. ${ }^{16,17}$ The ambassadors from the UK and Germany soon followed lead. Their pressure included the threat of stopping assistance from their countries to Bangladesh. Similarly, the multinationals threatened explicitly to stop the supply of medicines to the country completely. However, it was carefully crafted by an expert committee consisting of Professor Nurul Islam of Dhaka University, Zafrullah Chowduhry and other six professionals, such as military surgeons, with considerable experience and expertise. ${ }^{30}$ Drugs Act, 1982 is the key regulation relating to pharmaceuticals includes in Bangladesh. A regulatory agency is a public authority or government agency responsible for exercising autonomous authority over some area of human activity in a regulatory or supervisory capacity. Two organizations regulate drugs and pharmacies in Bangladesh, ${ }^{31}$ one "The Directorate General of Drug Administration (DGDA) "and another one is "The Pharmacy Council of Bangladesh (PCB)". Currently, there are 12 public universities and 31 private universities in Bangladesh offering Bachelor of Pharmacy and Masters of Pharmacy programs. ${ }^{22}$ From 2012 to 2017, historical five years CAGR was $15 \%$ and from 2014 to 2017, historical three years CAGR was $21 \% .{ }^{25}$ Recently, extension of the TRIPS deadline from 2016 to $2033 .{ }^{32}$ Bioequivalence study is the core of registration of any product in many of the moderately regulated and regulated countries of the world. So, the stakeholders should take initiatives to establish bioequivalence test facilities as soon as possible. Recently, NCL (National Control Laboratory) has been established and equipped with many modern instruments, but there are very few trained personnel to operate these. ${ }^{33}$ The API Park should be completed as early as possible with the intervention of government. Strict application of standard operating procedure in all aspects of production. Promoting knowledgebased marketing strategy and establishment of bioequivalence test facilities, Establishment of CRO (Clinical Research Organization) to conduct clinical trials. Practicing strict rules and regulations to fight against counterfeit drugs. Establishment of hospital pharmacy and making people more health conscious. Export Promotion Bureau (EPB) can play an effective role by arranging international fair frequently. Proper selection of raw materials and machineries for better product quality. More attention should be given to research and development sector.

\section{CONCLUSION}

Bangladesh has built a strong baseline and going towards the self-sufficiency for the production of medicine. Before 1982, location of industries has tended to be urban-based. Now, we getting the opportunity of patent exemption by the TRIPS until 2033 and the government have started the process of constructing an active pharmaceutical ingredient industrial park in Munshiganj. Thus, the future holds good for the local manufacturers as Bangladesh's pharma market is becoming a potential hub for generics. The government should really be attentive to remove all the obstacles and solve all the problems to see highest spectacle of pharmaceutical sector as a vital player in international market.

\section{ACKNOWLEDGEMENT}

The authors would like to express their heartfelt obligation, indebtedness, gramercy and profound appreciation are made to Department of Pharmacy, Noakhali Science and Technology University, Sonapur-3814, Noakhali, Bangladesh for their general facilities continuous support, untiring inspiration, scholastic supervision, constructive criticism, affectionate feeling and optimistic counseling for the conduction of this study.

\section{CONFLICT OF INTEREST}

The authors declare they have no competing interests.

\section{ABBREVIATIONS}

US-FDA: United States- food and drug administration; UK-MHRA: United Kingdom- medicines and healthcare products regulatory agency; TGA: Therapeutic goods administration; EU: European Union; GDP: Gross domestic product; MNCs: Multinational companies; DGDA: Director general of drug administration of Bangladesh; APIs: Active pharmaceutical ingredients; NDP: National drug policy; DCO: Drugs control ordinance; PCB: Pharmacy council of Bangladesh; BPS: Bangladesh pharmaceutical society; BCDS: Bangladesh chemists and druggists society; ECNEC: Executive committee of the national economic council; BAPI: Bangladesh association of pharmaceutical industries; 
CAGR: Compound annual growth rate; NCL: National control laboratory; CRO: Clinical research organization; EPB: Export promotion bureau; TRIPS: Trade related aspects of intellectual property rights.

\section{REFERENCES}

1. Annual-Report-2016-2017.pdf. [cited 2019 May 29]. Available from: https://renata-ltd.com/wp-content/uploads/2017/11/Annual-Report-2016-2017.pdf

2. Bangladesh's Burgeoning Pharmaceutical Sector: Ruling Local Market, Stock Business and Expanding Abroad. Dhaka Tribune. 2018. [cited 2019 Jun 1]. Available from: https://www.dhakatribune.com/business/stock/2018/11/03/bangladesh-s-burgeoning-pharmaceutical-sector-ruling-local-market-stock-businessand-expanding-abroad

3. A Glance at Two Success Stories. The Daily Star. 2018. [cited 2019 May 31]. Available from: https://www.thedailystar.net/supplements/building-moderneconomy/glance-two-success-stories-1536517

4. Assignment on Pharmaceuticals Sector of Bangladesh. Assignment Point. 2013. [cited 2019 May 31]. Available from: https://www.assignmentpoint.com/ science/pharmacy/assignment-on-pharmaceuticals-sector-of-bangladesh.html

5. Reich MR. Bangladesh Pharmaceutical Policy and Politics. Health Policy Plan. 1994;9(2):130-43

6. Pharmaceutical Industry-Banglapedia. [cited 2019 May 31]. Available from: http://en.banglapedia.org/index.php?title=Pharmaceutical_Industry

7. Recruitment Process of Square Pharmaceutical Limited. Assignment Point. [cited 2019 May 31]. Available from:https://www.assignmentpoint.com/business/ human-resource-management/recruitment-process-of-square-pharmaceuticallimited.html

8. On a National Drug Policy for Bangladesh. N Islam. 1984. [cited 2019 May 31] Available from: https://journals.sagepub.com/doi/10.1177/004947558401400103

9. How to Make 2018 a Successful Year for Pharmaceuticals. Dhaka Tribune. [cited 2019 May 31]. Available from: https://www.dhakatribune.com/business/2018/01/02/make-2018-successful-year-pharmaceuticals/

10. Sultana J. Future Prospects and Barriers of Pharmaceutical Industries in Bangladesh. Bangladesh Pharm J. 2016;19(1):53-7.

11. Bangladesh Association of Pharmaceutical Industries. [cited 2019 May 31] Available from: http://www.bapi-bd.com/

12. Hossain MM, Shoaib SM. Role of Pharmaceutical Sector in the National Economy of Bangladesh. WJPPS. 2014;3(2):951-60.

13. Registration Dashboard. [cited 2019 May 31]. Available from: http://www.dgda. gov.bd/index.php/registration-dashboard

14. Samia S, Rahat S. The Factors Influencing Turnover Intention among Employees: A Case Study on Pharmaceutical Company of Bangladesh. In Higher Education and Innovation Group in Education. 2017;8(9):49-55. [cited 2019 May 31]. Available from: http://heaig.org/images/proceedings_pdf/H0117510.pdf

15. Window of Opportunity for the Pharma Industry. The Daily Star. [cited 2019 May 31]. Available from: https://www.thedailystar.net/supplements/25th-anniversary-special-part-2/window-opportunity-the-pharma-industry-210937

16. Chowdhury Z. The Politics of Essential Drugs: The Makings of a Successful Health Strategy: Lessons from Bangladesh. London; Atlantic Highlands, N.J: Zed Books. 1995;192.

17. MdNazmul H, Mazharul ISM, Anzir M, MdAriful IR. Indigenous Resource Usage in the Pharmaceutical Industry in Bangladesh: A Descriptive Approach to Explain the Industry Scopes. International Journal of Scientific and Engineering Research. 2011;2(7):1-9. [cited 2019 May 31]. Available from: https://www.ijser.
org/paper/Indigenous_resource_usage_in_the_pharmaceuticals_industry_in Bangladesh_A_descriptive_approach_to_explain_the_industry_scopes.html

18. Huda S. Location of Drugs and Pharmaceutical Industries in Bangladesh. Bangladesh University of Engineering and Technology. 1993;1-76. Available from: http://lib.buet.ac.bd:8080/xmlui/handle/123456789/1058

19. Bangladesh Medical and Pharmaceutical Industry Handbook Volume 1 Pharmaceutical Industry: Strategic Information, Regulations and Contacts by Int'| Business Publications USA (Paperback). Lulu. 2011:1:284. [cited 2019 May 31]. Available from: http://www.lulu.com/shop/intl-business-publications-usa/ bangladesh-medical-and-pharmaceutical-industry-handbook-volume-1-pharmaceutical-industry-strategic-information-regulations-contacts/paperback/product-15066883.html

20. Azam M. Intellectual Property and Public Health in the Developing World. Open Book Publishers. 2016. [cited 2019 May 31]. Available from: https://www.openbookpublishers.com/product/476

21. Nayan M. History of Pharmacy Education in Bangladesh. [cited 2019 May 31]; Available from: https://www.academia.edu/6968154/History_of_Pharmacy_Education_in_Bangladesh

22. Rasel TA. Pharmacy and Pharmacists in Context of Bangladesh: The Asian Age Online, Bangladesh. The Asian Age. 2018. [cited 2019 May 31]. Available from: http://dailyasianage.com/news/153071/pharmacy-and-pharmacists-in-contextof-bangladesh

23. Labu ZK. Present Status of Pharmacy Education and Future Prospects and Challenge of Pharmacy Practice in Bangladesh. J Drug Discov Ther. 2013;1(3):1-9. [cited 2019 May 31]. Available from: http://jddt.in/index.php/jddt/article/view/26

24. Alam GM, Al-Amin AQ. Role of Pharmacy Education in National Development of Bangladesh: A Scope for Public and Private Sectors. IJPER. 2014;48(4):11-21.

25. Pharmaceuticals Industry of Bangladesh.pdf. [cited 2019 May 31]. Available from: http://www.eblsecurities.com/AM_Resources/AM_ResearchReports/ SectorReport/Pharmaceuticals\%20Industry\%20of\%20Bangladesh.pdf

26. Exploring Global Opportunities for the Bangladesh Pharmaceutical Industry Light Castle Partners. 2016. [cited 2019 May 31]. Available from: https://www. lightcastlebd.com/insights/2016/11/27/exploring-global-opportunities-for-thebangladesh-pharmaceutical-industry

27. Islam S, Rahman A, Mahmood AKA. Bangladesh Pharmaceutical Industry: Perspective and the Prospects. Bangladesh J Med Sci. 2018;17(4):519-25.

28. Industrial Park for Pharma Ingredients Finally Taking Shape. The Daily Star. 2017. [cited 2019 May 31]. Available from: https://www.thedailystar.net/business/ industrial-park-pharma-ingredients-finally-taking-shape-1475617

29. Alam M. Export Potentiality of Pharmaceutical Goods in Bangladesh. Business presented at; 19:28:38 UTC. 2014. [cited 2019 May 31]. Available from: https:// www.slideshare.net/ShahedAlam/export-potentiality-of-pharmaceutical-goodsin-bangladesh-50984661

30. State Building and Development: $1^{\text {st }}$ Edition (Paperback) - Routledge. Routledge. com. [cited 2019 May 31]. Available from: https://www.routledge.com/StateBuilding-and-Development-1 st-Edition/Otsuka-Shiraishi/p/book/9781138918122

31. Pharmaceutical Regulatory Affairs: Open Access. Problems of Enforcements of Regulations on Pharmaceutical Industry in Bangladesh. 2014;3(3):80. [cited 2019 May 31]. Available from: https://www.omicsonline.org/proceedings/ problems-of-enforcements-of-regulations-on-pharmaceutical-industry-in-bangladesh-19054.html

32. Sultana T, Paul A, Islam S. Bangladesh to Benefit from TRIPS Waiver: An Academic Perspective. 2017;3(2):8.

33. Sultana J. Future Prospects and Barriers of Pharmaceutical Industries in Bangladesh. Bangladesh Pharm J. 2016;19(1):53-7.

Cite this article: Mosharraf S, Hossain MS, Barek MA, H Das, Ripon MAR. A Review on Revolution of Pharmaceutical Sector in Bangladesh after Liberation War and Future Prospects and Challenges. Int. J. Pharm. Investigation. 2019;9(3):89-92. 